\title{
Controle alternativo de Planococcus citri (Risso, 1813) com extratos aquosos de pinhão-manso
}

\author{
Alternative control Planococcus citri (Risso, 1813) \\ with aqueous extracts of Jatropha
}

\author{
Anderson Mathias Holtz², Mayara Loss Franzin ${ }^{2 *}$, Hágabo Honorato de Paulo², \\ Jéssica Mayara Coffler Botti ${ }^{2}$, Johnatan Jair de Paula Marchiori ${ }^{1}$, Érica Gonçalves Pacheco'
}

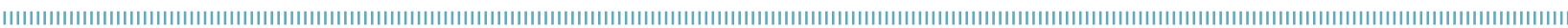

RESUMO: A cochonilha-da-roseta, Planococcus citri (Risso, 1813) (Hemiptera: Pseudococcidae), constitui um problema fitossanitário na cultura do café. $\mathrm{O}$ controle mais usual dessa praga é o químico, o que pode acarretar, além de problemas socioambientais, a seleção de indivíduos resistentes. Com isso, torna-se necessário o controle alternativo. Dessa forma, o objetivo deste trabalho foi estudar, em condiçóes de laboratório, o potencial inseticida de diferentes partes da planta de Jatropha curcas, em variadas concentraçóes, sobre P. citri. Discos de folhas de café conilon com 10 cochonilhas (ninfas e adultos) foram pulverizados direta e indiretamente com auxílio da torre de Potter, com pressáo de $15 \mathrm{Lb} / \mathrm{pol}^{2}$, aplicando $6 \mathrm{~mL}$ de solução por repetição. Testaram-se sete concentraçóes do óleo e de extratos, tanto na aplicaçáo direta quanto na indireta, com 10 repetiçóes por tratamento, sendo avaliada a mortalidade em funçáo do tempo. Todas as estruturas de pinhão-manso, em ambas as vias de aplicaçáo, apresentaram índices de mortalidade satisfatórios de $P$. citri, alcançando $91,6 \%$ de mortalidade nas concentraçôes de 1,5, 2,0 e 3,0\% do óleo na aplicação direta.

PALAVRAS-CHAVE: Jatropha curcas; inseticida botânico; cochonilha-da-roseta.

\begin{abstract}
The Planococcus citri (Risso, 1813) (Hemiptera: Pseudococcidae) is a phytosanitary problem in the coffee's cultivation. The most used type of control for this pest is the chemical one, which leads to the selection of resistant individuals, as well as social and environmental problems. Therefore, it is necessary to control the alternative. Thus, this paper had the aim of studying the potential insecticide in different parts of the plant Jatropha curcas, in some concentrations, over the $P$. citri. Dices of leaf containing 10 $P$. citri (nymphs and adults) were directly and indirectly sprayed with the Potter Tower's assistance, on the pressure at $15 \mathrm{Lb} / \mathrm{pol}^{2}$, applying $6 \mathrm{~mL}$ of solution per repetition. Seven concentrations of oil and extracts were tested, and the mortality was evaluated in function of time. All physic nut's structures in both routes of administration showed satisfactory mortality $P$. citri, reaching $91.6 \%$ mortality at the concentrations of $1.5,2.0$ e $3.0 \%$ oil in the direct application.
\end{abstract}

KEYWORDS: Jatropha curcas; botanical insecticide; Planococcus citri. 


\section{INTRODUÇÃO}

A cochonilha-da-roseta, Planococcus citri (Risso, 1813) (Hemiptera: Pseudococcidae), acarreta sérias injúrias na cultura do café conilon, ocasionando queda na produtividade (ForNazier et al., 2004). Seu ataque ocorre diretamente aos botôes florais e aos frutos em formação e crescimento, causando sua queda. Além disso, em frutos mais desenvolvidos provoca "chochamento" (ForNAZIER et al., 2001).

Para o controle dessa praga, ainda não há produtos químicos registrados na cultura do café. Isso estimula o uso de produtos náo registrados, o que pode suceder no ressurgimento da praga-alvo, bem como no aparecimento de novas pragas, já que a maioria dos produtos utilizados possui amplo espectro biológico e persistência no ambiente, prejudicando assim a saúde do consumidor e dos profissionais envolvidos nos processos de produçáo (BRITO et al., 2004).

Como medidas alternativas para o controle de pragas, vêm sendo realizadas pesquisas relacionadas à utilizaçáo de substâncias com potencial inseticida obtidas de plantas, demonstrando eficiência satisfatória. Os primeiros produtos extraídos de plantas usados na agricultura foram a nicotina, extraída do fumo, Nicotiana tabacum (Solanaceae), e a piretrina, derivada do piretro, Chrysanthemum cinerariaefolium (Asteraceae) (LAGUnes; Rodríguez, 1989).

Vendramim et al. (2003) e Vendramim; Tavares (2005) têm estudado várias espécies vegetais com atividades inseticidas e acaricidas, sendo uma delas o Chenopodium ambrosioides, no controle do gorgulho-do-milho, Sitophilus zeamais. O Chenopodium é um gênero encontrado em quase todo o mundo e contém substâncias com propriedades fungicidas, bactericidas, nematicidas e inseticidas (LoREnzI; Matos, 2002). Sapindus saponaria, também utilizada no controle de pragas, consiste numa espécie que contém saponinas, eficazes no controle de carunchos, em grãos de milho e feijão (Grange; Ahmed, 1988).

Outro exemplo de plantas inseticidas são as pimenteiras, principalmente as do gênero Piper. Elas apresentam em sua estrutura uma série de amidas (a piperina, por exemplo), as quais agem como neurotoxinas e afetam as funçôes do sistema nervoso central, causando rápida paralisia do inseto (SсOTT et al., 2002). A citronela, Cymbopogon winterianus, também possui óleos com propriedades repelentes, tendo mais de 80 componentes principais, entre eles o citronelal, o geraniol e o limoneno (Maia et al., 1998).

As substâncias de origem vegetal oferecem diversas vantagens quando comparadas aos inseticidas sintéticos: baixa persistência e acumulação do pesticida no ambiente, seletividade, são biodegradáveis e náo apresentam os conhecidos efeitos colaterais típicos dos inseticidas convencionais (GIONETTO; Chávez, 2000).
Contudo, para o pinháo-manso (Jatropha curcas), são objetos de estudo as formas de ação e os efeitos das substâncias com propriedades inseticidas presentes no óleo e em extratos obtidos de várias partes da planta (UnGaro; Regitano Neto, 2007). Os seus efeitos, a exemplo de outras substâncias orgânicas com propriedades toxicológicas, podem ocorrer sob diferentes formas. Tais substâncias provavelmente atuam sobre o metabolismo, provocando inibiçáo alimentar, repelência, ação inibitória ou supressora da oviposição, e induzem a produção de ovos inférteis, a inibição do desenvolvimento de larvas, ninfas e pupas ou a inibição do ato do acasalamento (Ungaro; Regitano Neto, 2007).

Dessa forma, este trabalho visou avaliar a potencialidade, em condiçôes de laboratório, do uso de substâncias (extratos e óleos) da espécie J. curcas, quanto à sua atividade inseticida sobre $P$. citri na cultura do café.

\section{MATERIAL E MÉTODOS}

O experimento foi realizado no Laboratório de Entomologia do Instituto Federal de Educação, Ciência e Tecnologia (IFES) do Espírito Santo, Campus Itapina, em câmaras climatizadas a $25 \pm 1{ }^{\circ} \mathrm{C}, \mathrm{UR} 70 \pm 10 \%$ e fotofase de $12 \mathrm{~h}$. Para isso, utilizou-se a espécie J. curcas, na forma de extrato e óleo da semente e de partes de sua estrutura, para o estudo da atividade inseticida.

\section{Criação e manutenção da cochonilha-da-roseta}

Foram utilizadas batatas inteiras, com peso entre 100 e $200 \mathrm{~g}$, e com bastantes gemas, do cultivar monalisa. As bandejas continham de 20 a 25 batatas. No fundo de cada bandeja foram feitas perfuraçóes para evitar o excesso de umidade e o apodrecimento das batatas. Adultos de $P$. citri foram coletados em campo, em plantas de café conilon (Coffea canephora), e transferidos para tubérculos de batata. A criaçáo foi mantida em sala climatizada com $25 \pm 2{ }^{\circ} \mathrm{C}$, UR $70 \pm 10 \%$ e fotofase de $12 \mathrm{~h}$.

\section{Confecção dos extratos vegetais de pinhão-manso}

Folhas, caule sem casca, casca do caule, casca dos frutos e sementes de pinhão-manso foram coletadas no IFES, Campus Itapina. $\mathrm{O}$ material foi colocado para secar em estufa com circulação de ar forçado a $40^{\circ} \mathrm{C}$ por $72 \mathrm{~h}$. As diferentes partes da planta foram submetidas à moagem em um moinho de facas, obtendo-se um pó fino. Obteve-se o óleo das sementes mediante prensagem a frio. 
Para a obtenção da solução aquosa, utilizaram-se 0,5 , $1,0,1,5,2,0,2,5$ e 3,0 $\mathrm{g}$ de pó das diferentes estruturas vegetais e $0,5,1,0,1,5,2,0,2,5$ e 3,0 mL de óleo em $100 \mathrm{~mL}$ do solvente (água destilada). Para a diluição e aplicação do óleo e dos extratos, foi empregado espalhante adesivo Tween ${ }^{\circledR} 80$ $(0,05 \%)$. Em seguida, a mistura permaneceu sob agitação em mesa agitadora por $2 \mathrm{~h}$, à temperatura ambiente. Após esse período, o material ficou em repouso por aproximadamente 20 min para decantação, sendo em seguida separado o sobrenadante da parte sólida por intermédio de filtração simples, por um funil com algodão.

As concentraçóes de extratos aquosos de cada estrutura vegetal e para o óleo foram $0,0,0,5,1,0,1,5,2,0,2,5$ e 3,0\% (peso/volume).

\section{Teste de aplicação direta}

Cada uma das concentraçôes de óleo e extrato foi aplicada sobre 10 fêmeas, do primeiro instar à adulta, de $P$. citri, que foram mantidos em placas de Petri $(10,0 \times 1,2 \mathrm{~cm})$ sobre discos de folha de café conilon ( $4 \mathrm{~cm}$ de diâmetro) apoiados sobre uma camada de $0,5 \mathrm{~cm}$ de solução de ágar-ágar e vaselina sólida ao redor do disco para manter a turgência. As placas foram fechadas com filme plástico de policloreto de vinila (PVC). Aplicaram-se as soluçóes diretamente sobre os insetos nas placas de Petri, utilizando uma torre de Potter, com pressão exercida de $15 \mathrm{Lb} / \mathrm{pol}^{2}$ e volume de $6 \mathrm{~mL}$ de solução em cada disco.

O experimento foi instalado em delineamento inteiramente casualizado com 35 tratamentos (cinco extratos vegetais $\times$ sete concentraçóes) com 10 repetiçóes (placas de Petri). Como testemunha, foi aplicada água destilada com espalhante adesivo Tween ${ }^{\oplus} 80$ (0,05\%).

No decorrer do experimento foram realizadas avaliaçóes 24, 48 e $72 \mathrm{~h}$ após as aplicaçóes das diferentes concentraçóes de extratos e óleos de cada estrutura vegetal de J. curcas. Foi avaliado o número de insetos mortos. Para a avaliação, empregou-se o microscópio estereoscópico. Os dados obtidos das diferentes estruturas e dos tipos de aplicação foram submetidos ao teste de médias, e as diferentes concentraçôes, à análise de regressão linear.

\section{Teste de aplicação indireta}

O teste de ação indireta foi realizado sob as mesmas condiçôes do teste de aplicação direta. O número de indivíduos de $P$. citri utilizados em cada tratamento foi idêntico ao do teste já descrito. Contudo, neste experimento foi feita a pulverização de cada solução sobre o disco de folha, no interior das placas de Petri. Feito esse procedimento, foram inoculadas as fêmeas de P. citri. O procedimento de avaliação e análise dos dados foi o mesmo do teste anterior.

\section{RESULTADOS E DISCUSSÃO}

Houve interação entre os fatores extrato de pinhão-manso, concentração dos extratos e formas de aplicação (F20, $468=2,83 ; \mathrm{p}<0,0001)$. Quando se viu diferença na mortalidade de $P$. citri entre as formas de aplicação, observou-se maior mortalidade na aplicaçáo direta, exceto na concentração de $0,5 \%$ do extrato de caule (Tabela 1 ). Resultados semelhantes foram encontrados em um estudo com óleo de mamona e aplicaçóes direta e indireta, sobre a broca-do-café, Hypothenemus hampei (Ferrari, 1867), com maior índice de mortalidade na aplicação direta, chegando à mortalidade de 67,3\% dos indivíduos na concentração de 3,0\% (Celestino, 2011).

Provavelmente, a tendência de as maiores mortalidades serem alcançadas na aplicação direta ocorre porque as moléculas com propriedades inseticidas contidas nos extratos de pinhão-manso, semelhantemente à rotenona (presente em algumas espécies de plantas da família Fabaceae), são absorvidas pelo tegumento do inseto, afetando o sistema nervoso central, provocando rapidamente sua morte (Aguiar-Menezes, 2005). Já na aplicação indireta, as moléculas do extrato passam por todo o processo digestório do inseto para que a incorporação e a ação das moléculas com propriedades inseticidas do produto ajam nos sistemas vitais da praga (Kathrina; Antonio, 2004; Aguiar-Menezes, 2005).

A mortalidade de $P$. citri diferiu entre os extratos de pinhão-manso em todas as concentraçóes avaliadas. Na concentração de $0,5 \%$, os extratos de óleo, folha e casca do caule de pinhão-manso na forma de aplicação direta sobre a praga foram os que proporcionaram mais mortalidade de $P$. citri $(56,7,28,4$ e $41,2 \%$, respectivamente). Na aplicação indireta, o extrato de caule foi o que causou mais mortalidade da praga $(57,2 \%)$, e com os demais extratos a mortalidade variou de 9,3 a $39,0 \%$ (Tabela 1 ).

Na concentração de 1,0\%, verificaram-se as maiores mortalidades na forma de aplicação direta nos tratamentos com os extratos de óleo e caule, no entanto os extratos de óleo, folha e casca do fruto foram os que causaram mais mortalidade na aplicação indireta (Tabela 1).

Considerando a concentração de 1,5\%, na aplicação direta, o óleo foi o extrato mais eficiente para o controle de $P$. citri. $\mathrm{Na}$ aplicação indireta esse extrato causou mais mortalidade, porém não diferiu daquela encontrada para o da casca do fruto (Tabela 1). Avaliando a concentração de 2,0\%, o óleo na aplicação direta também foi o extrato mais eficiente. Contudo, na aplicação indireta, os extratos de óleo, folha e casca do fruto de pinhão-manso foram os que proporcionarama mais mortalidade da cochonilha (Tabela 1).

Entretanto, a eficiência da aplicação direta de todos os extratos foi a mesma na concentração de $2,5 \%$, sendo 
observadas mortalidades de $P$. citri variando de 66,7 a $83,2 \%$. Ao averiguar a aplicação indireta, os extratos mais eficazes foram os de óleo, folha e casca do fruto (Tabela 1). $\mathrm{Na}$ concentraçáo de $3 \%$, as maiores mortalidades na aplicação direta foram proporcionadas pelos extratos de óleo, folha, casca do fruto e casca do caule, porém, na aplicaçáo indireta, os extratos mais eficientes foram os de óleo e casca do fruto (Tabela 1).

Exceto na concentração de $0,5 \%$ na forma de aplicação indireta, a mortalidade causada pelo óleo de pinhão-manso esteve entre os maiores índices (Tabela 1). HARBorne (1972) afirmou que a distribuição de substâncias tóxicas nas diferentes partes das plantas não é uniforme, nem no aspecto qualitativo nem no quantitativo. Os ésteres de forbol (diterpenos) são as substâncias mais tóxicas presentes no pinhão-manso (GonçALVEs et al., 2009), que são bastante solúveis em óleo, portanto estão presentes de forma concentrada nele (GANDhi et al., 1995). Diante disso, é possível que o fato de os maiores índices de mortalidade da cochonilha-da-roseta terem sido alcançados com o óleo se deve à presença mais concentrada de ésteres de forbol nele, em relação às demais partes da planta.

Alguns extratos de pinháo-manso não apresentaram efeito dose-resposta sobre a mortalidade de P. citri (Fig. 1). A mortalidade ocasionada pelo óleo de pinhão-manso na aplicação direta não se ajustou a nenhum modelo matemático, porém manteve os mais altos níveis de mortalidade. Na aplicaçáo indireta, a mortalidade de $P$. citri aumentou em função das concentraçôes de óleo de pinhão-manso, e os dados ajustaram-se ao modelo linear ( $\mathrm{R} 2=87,6 \%$ ), sendo observada mortalidade máxima de $88,4 \%$.

A mortalidade de $P$. citri também se elevou em função das concentraçôes do extrato de folha, e os dados ajustaram-se ao modelo linear, tanto na aplicação direta quanto na indireta ( $\mathrm{R} 2=97,5$ e $96,8 \%$, respectivamente), as quais causaram mortalidade máxima de 76,1 e 65,6\%, nessa ordem. A resposta do extrato de casca da semente foi semelhante ao extrato de folha, sendo constatados coeficientes de correlaçáo nas aplicaçóes direta e indireta de 96,9 e 91,8\%, e mortalidade máxima de 77,0 e 84,9\%, respectivamente. Contudo, a mortalidade da praga ocasionada pelos extratos de casca do caule e caule, em ambas as formas de aplicação, não se ajustou a nenhum modelo matemático, sendo registradas menores mortalidades.

Soluções mais concentradas possuem maior número de moléculas do soluto em relação a moléculas do solvente (Peruzzo; Canto, 2003). Sendo assim, à medida que se aumenta a concentração da solução de extratos de pinhão-manso, aumenta-se o número de moléculas das substâncias tóxicas. Possivelmente, o aumento da mortalidade de P. citri com o aumento da concentração do extrato está ligado ao maior número de moléculas tóxicas.

Tabela 1. Mortalidade média corrigida (\%) ( \pm EP) de Planococcus citri 72 h após aplicação dos extratos de pinhão-manso, a diferentes concentrações, com aplicações direta e indireta.

\begin{tabular}{|c|c|c|c|c|c|}
\hline \multirow{2}{*}{$\begin{array}{l}\text { Concentração/ } \\
\text { forma de aplicação }\end{array}$} & \multicolumn{5}{|c|}{$0,5 \%^{1,2}$} \\
\hline & Óleo & Folha & Casca do fruto & Casca do caule & Caule \\
\hline Direta & $56,7 \pm 3,68 \mathrm{Aa}$ & $28,4 \pm 4,49 A a$ & $13,7 \pm 4,21 \mathrm{Ab}$ & $41,2 \pm 10,71 \mathrm{Aa}$ & $12,8 \pm 10,25 B b$ \\
\hline \multirow[t]{2}{*}{ Indireta } & $29,1 \pm 4,73 \mathrm{Bb}$ & $20,4 \pm 2,37 \mathrm{Ab}$ & $9,3 \pm 4,32 \mathrm{Ac}$ & $39,0 \pm 12,70 A b$ & $57,2 \pm 11,20 A a$ \\
\hline & \multicolumn{5}{|c|}{$1,0 \%$} \\
\hline Direta & $56,6 \pm 5,45 \mathrm{Aa}$ & $35,2 \pm 4,49 A b$ & $35,6 \pm 6,23 \mathrm{Ab}$ & $35,4 \pm 11,91 \mathrm{Ab}$ & $60,8 \pm 13,19 \mathrm{Aa}$ \\
\hline \multirow[t]{2}{*}{ Indireta } & $54,7 \pm 4,73 \mathrm{Aa}$ & $33,3 \pm 4,18 \mathrm{Aa}$ & $44,2 \pm 6,44 \mathrm{Aa}$ & $18,4 \pm 13,91 \mathrm{Ab}$ & $16,4 \pm 14,09 \mathrm{Bb}$ \\
\hline & \multicolumn{5}{|c|}{$1,5 \%$} \\
\hline Direta & $91,6 \pm 1,83 \mathrm{Aa}$ & $50,0 \pm 6,16 \mathrm{Ab}$ & $46,0 \pm 6,65 \mathrm{Ab}$ & $27,2 \pm 12,03 \mathrm{Ac}$ & $58,2 \pm 12,68 \mathrm{Ab}$ \\
\hline \multirow[t]{2}{*}{ Indireta } & $70,9 \pm 4,97 \mathrm{Ba}$ & $33,3 \pm 4,75 \mathrm{Ab}$ & $47,7 \pm 7,80 A a$ & $8,7 \pm 6,01 \mathrm{Ac}$ & $26,6 \pm 13,94 \mathrm{Bb}$ \\
\hline & \multicolumn{5}{|c|}{$2,0 \%$} \\
\hline Direta & $91,6 \pm 3,14 \mathrm{Aa}$ & $63,4 \pm 6,52 \mathrm{Ab}$ & $59,8 \pm 5,21 \mathrm{Ab}$ & $65,3 \pm 6,30 A b$ & $28,2 \pm 13,78 \mathrm{Ac}$ \\
\hline \multirow[t]{2}{*}{ Indireta } & $65,1 \pm 5,48 \mathrm{Ba}$ & $48,4 \pm 6,17 \mathrm{Aa}$ & $67,4 \pm 5,42 \mathrm{Aa}$ & $21,5 \pm 13,3 \mathrm{Bb}$ & $3,3 \pm 3,3 \mathrm{OBc}$ \\
\hline & \multicolumn{5}{|c|}{$2,5 \%$} \\
\hline Direta & $83,2 \pm 5,73 \mathrm{Aa}$ & $67,0 \pm 6,21 \mathrm{Aa}$ & $66,7 \pm 10,21 \mathrm{Aa}$ & $77,1 \pm 8,91 \mathrm{Aa}$ & $66,9 \pm 16,43 \mathrm{Aa}$ \\
\hline \multirow[t]{2}{*}{ Indireta } & $84,9 \pm 4,27 \mathrm{Aa}$ & $59,1 \pm 5,02 \mathrm{Aa}$ & $70,9 \pm 7,20 A a-$ & $31,5 \pm 17,79 \mathrm{Bb}$ & $10,6 \pm 3,34 \mathrm{Bb}$ \\
\hline & \multicolumn{5}{|c|}{$3,0 \%$} \\
\hline Direta & $91,6 \pm 3,61 \mathrm{Aa}$ & $76,1 \pm 5,20 A a$ & $77,0 \pm 7,27 \mathrm{Aa}$ & $67,0 \pm 11,22 \mathrm{Aa}$ & $32,6 \pm 17,79 \mathrm{Ab}$ \\
\hline Indireta & $88,4 \pm 4,60 A a$ & $65,6 \pm 5,73 A b$ & $84,9 \pm 5,76 \mathrm{Aa}$ & $13,1 \pm 6,58 \mathrm{Bc}$ & $31,1 \pm 9,64 \mathrm{Ac}$ \\
\hline
\end{tabular}

'Médias seguidas pela mesma letra minúscula na linha e letra maiúscula na coluna não diferem entre si pelo teste de Scott-Knott, a $5 \%$ de significância; ${ }^{2}$ dados transformados para arc sen $(x / 100) 0,5$. 

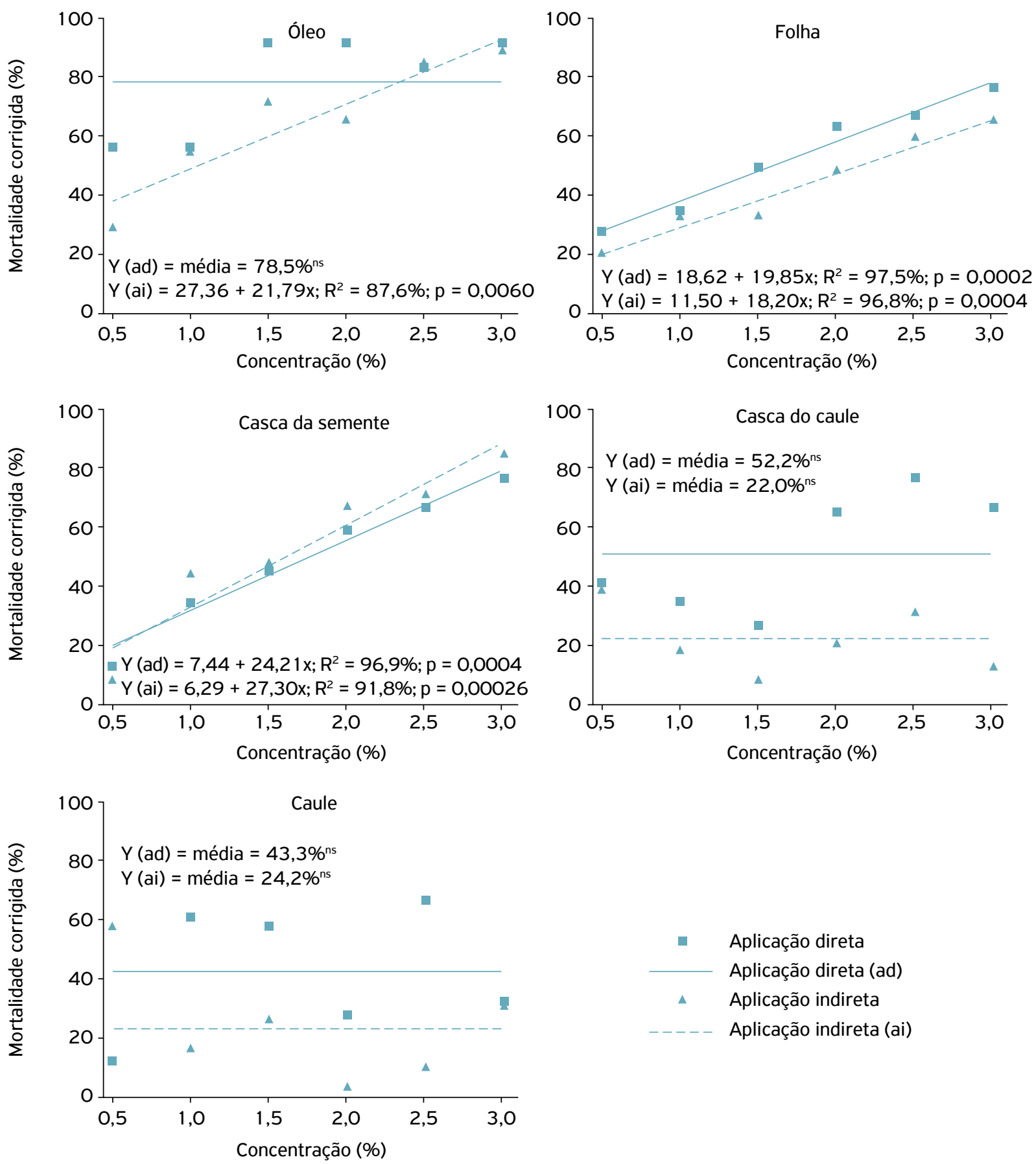

ns: não significativo.

Figura 1. Mortalidade corrigida de Planococcus citri tratada com extratos de Jatropha curcas, a diferentes concentrações, pelas aplicações direta e indireta, após $72 \mathrm{~h}$. Dados transformados para arc sen $(\mathrm{x} / 100)^{0,5}$.

\section{CONCLUSÃO}

Todas as estruturas de $J$. curcas estudadas, em ambas as vias de aplicação, apresentam potencial inseticida no controle de $P$. citri. Dessa forma, a utilização de $J$. curcas é promissora para o controle da cochonilha-da-roseta na cultura do café.

\section{AGRADECIMENTOS}

Ao Conselho Nacional de Desenvolvimento Científico e Tecnológico (CNPq), ao Núcleo de Desenvolvimento Científico e Tecnológico em Manejo Fitossanitário de Pragas e Doenças (NUDEMAFI) e ao Instituto Federal do Espírito Santo (IFES), o apoio indispensável à execução do presente trabalho. 
AGUIAR-MENEZES, E.L. Inseticidas botânicos: seus princípios ativos, modo de ação e uso agrícola. Seropédica: Embrapa Agrobiologia, 2005. 58p. (Documentos, 205).

BRITO, G.G.; COSTA, E.C.; MAZIERO, H.; BRITO, A.B.; DÖRR, F.A. Preferência da broca-das-cucurbitáceas [Diaphania nitidalis Cramer, 1782 (Lepidoptera: Pyralidae)] por cultivares de pepineiro em ambiente protegido. Ciência Rural, Santa Maria, v.34, n.2, p.577-579, 2004.

CELESTINO, F.N. Potencial do óleo de mamona e associação com Beauveria bassiana (Bals.) Vuillemin visando o manejo da brocado-café. 2011 . Dissertação (Mestrado em Produção Vegetal) Centro de Ciências Agrárias, Universidade Federal do Espírito Santo, Alegre, 2011.

FORNAZIER, M.J.; FANTON, C.J.; MARTINS, D.S.; GOMES, W.R.; GOMES, M.A. Guia do cafeicultor: cochonilha da roseta do café conilon. São Gabriel: COOABRIEL, 2004. 7p.

FORNAZIER, M.J.; MARTINS, D.S.; CARMO, G.O.; DE MUNER, L.H.; SANTA CECÍLIA, L.V. Ocorrência de Planococcus minor Maskell, 1897 (Hemiptera: Pseudococcidae) em café na região sul do Espírito Santo. In: CONGRESSO BRASILEIRO DE PESQUISAS CAFEEIRAS, 27., 2001, Uberaba, MG. Resumos. Uberaba: 2001. p.250-251.

GANDHI, V.M.; CHERIAN, K.M.; MULKY, M.J. Toxicological studies on ratanjyot oil. Food and Chemical Toxicology, Oxford, v.33, n.1, p.39-42, 1995.

GIONETTO, F.; CHÁVEZ, E.C. Desarrollo actual de las investigaciones alelopáticas de la producción, de insecticidas botánicos en Michoacán (México). In: SIMPOSIO NACIONAL SOBRE SUBSTÁNCIAS VEGETALES Y MINERALES EN EL COMBATE DE PLAGAS, 6., 2000, Acapulco. Resumos. Acapulco: 2000. p.123-134.

GONÇALVES, S.B.; MENDONÇA S.; LAVIOLA, B.G. Substâncias tóxicas, alergênicas e antinutricionais presentes no pinhão-manso e seus derivados e procedimentos adequados ao manuseio. Circular Técnica, Brasília, 2009.

GRANGE, M.; AHMED, S. Handbook of plants with pest control properties. New York: John Wiley, 1988. 470p.

HARBORNE, J.B. Phytochemical ecology. London: Academic Press, 1972. 272p.
KATHRINA, G.A.; ANTONIO, L.P.J. Control biológico de insectos mediante extractos botánicos. In: CARBALLO, M.; GUAHARAY, F. (Eds.). Control biológico de plagas agrícolas. Managua: CATIE, 2004. p.137-160.

LAGUNES, T.A.; RODRÍGUEZ, H.C. Búsqueda de tecnologia apropriada para el combate de plagas del mais almacenado em condiciones rústicas. Chapingo: CONACYT, 1989. 150p.

LORENZI, H.; MATOS, F.J.A. Plantas medicinais do Brasil: nativas e exóticas. Nova Odessa: Instituto Plantarum de Estudos da Flora Ltda., 2002. 462p.

MAIA, N.B.; BOVI, O.A.; DUARTE, F.R.; CALHEIROS, M.B.P. Citronelade-java (Cymbopogon nardus Rendle). In: MAIA, N.B.; BOVI, O.A.; DUARTE, F.R.; CALHEIROS, M.B.P.Instruções agrícolas para as principais culturas econômicas. 6th.ed. Campinas: Instituto Agronômico, 1998. (Boletim 200). $11 \mathrm{p}$.

PERUZZO, F.M.; CANTO, E.L. Química na abordagem do cotidiano. São Paulo: Moderna, 2003.

SCOTT, I.M.; PUNIANI, E.; DURST, T.; PHELPS, D.; MERALI, S.; ASSABGUI, R.A.; SANCHEZ-VINDAS, P.; POVEDA, L.; PHILOGENE, B.J.; ARNASON, J.T. Insecticidal activity of piper tuberculatum Jacq. extracts: synergistic interaction of piperamides. Agriculture Forest Entomology, v.4, n.2, p.137-144, 2002. DOI: 10.1046/j.1461-9563.2002.00137.x

UNGARO, M.R.G.; REGITANO NETO, A. Considerações sobre pragas e doenças de pinhão manso no estado de São Paulo. In: CONGRESSO BRASILEIRO DE PLANTAS OLEAGINOSAS, ÓLEOS, GORDURAS E BIODIESEL, 4., 2007, Lavras, MG. Resumos. Lavras, 2007. 272p.

VENDRAMIM, J.D.; PROCÓPIO, S.O.; RIBEIRO JR., J.I.; SANTOS, J.B. Bioatividade de diversos pós de origem vegetal em relação a Sitophilus zeamais Mots. (Coleoptera: Curculionidae). Ciência e Agrotecnologia, Lavras, v.27, n.6, p.1231-1236, 2003. DOI: $10.1590 / \mathrm{S} 1413-70542003000600004$

VENDRAMIM, J.D.; TAVARES, M.A.G.C. Atividade inseticida da ervade-santa-maria Chenopodium ambrosioides L. (Chenopodiaceae) em relação a Sitophilus zeamais Mots., 1855 (Coleoptera: Curculionidae). Arquivos do Instituto Biológico, São Paulo, v.72, n. 1, p.51-55, 2005. 